\title{
Effects of an interdisciplinary weight loss program on fibroblast growth factor 21 and inflammatory biomarkers in women with overweight and obesity
}

\author{
Ana Raimunda Dâmaso' \\ https://0000-0001-7675-7470 \\ Paola Próspero Machado' \\ https://orcid. org/0000-0003-1426-6873 \\ Samantha Ottani Rhein ${ }^{1}$ \\ Samantha Ottani Rhein' \\ Deborah Cristina Landi Masquio² \\ https://orcid. org/0000-0003-0187-6402 \\ Lila Missae Oyama ${ }^{1,3}$ \\ https://orcid.org/0000-0002-7078-6526 \\ Valter Tadeu Boldarine ${ }^{1,3}$ \\ https://orcid. org/0000-0003-2686-7430 \\ Gabriela lervolino de Oliveira ${ }^{4}$ \\ https://orcid.org/0000-0002-2650-3461 \\ Lian Tock ${ }^{4}$ \\ https://orcid. org/0000-0003-0834-904X \\ David Thivel ${ }^{5}$ \\ https://orcid. org/0000-0003-4687-3555
}

Raquel Munhoz da Silveira Campos C $^{6,7}$

https://orcid.org/0000-0001-6132-4349

\begin{abstract}
Objective:To investigate the effects of an interdisciplinary intervention on biomarkers of inflammation and their relationship with fibroblast growth factor 21 (FGF21) concentrations in women with overweight and obesity. Subjects and methods: Thirty-one women were enrolled in a 12-week interdisciplinary weight loss program delivered by a team comprising an endocrinologist, nutritionist and exercise physiologist. Body composition; anthropometric measures; metabolic and inflammatory markers including adiponectin, leptin, and atrial natriuretic peptide (ANP) were assessed at baseline and post-therapy. The homeostasis model assessment of insulin resistance (HOMA-IR) and the homeostasis model assessment of adiponectin (HOMA-AD) were calculated. The participants were divided into two groups: those with increased FGF21, and those with decreased FGF21. Results: The sample comprised women aged $32 \pm 5$ years with a body mass index of $33.64 \pm 3.49 \mathrm{~kg} / \mathrm{m}^{2}$. Body weight, waist circumference and leptin concentration were decreased in the whole sample after therapy. However, only the group with an increase in FGF21 concentration presented significant improvements in adiponectin concentration and adiponectin/leptin ratio. Moreover, although there was a reduction of leptin in both groups, it was greater in the increased FGF21 groups. There was a reduction in ANP in the decreased FGF21 group. Conclusions: Changes in FGF21 concentrations were different among the women participating in the weight loss program, with some having increased levels and some reduced levels. Furthermore, improvements in adiponectin and the adiponectin/ leptin ratio were found only in the group with increased FGF21 concentration. Arch Endocrinol Metab. 2021;65(6):821-31
\end{abstract}

Keywords

Adiposity; inflammation; weight loss
1 Programa de Pós-graduação em Nutrição, Escola Paulista de Medicina, Universidade Federal de São Paulo, São Paulo, SP, Brasil ${ }^{2}$ Centro Universitário São Camilo, São Paulo, SP, Brasil ${ }^{3}$ Departamento de Fisiologia Escola Paulista de Medicina, Universidade Federal de São Paulo, São Paulo, SP, Brasil

${ }^{4}$ Grupo de Estudos da Obesidade (GEO/UNIFESP), Escola Paulista de Medicina, São Paulo, SP, Brasil ${ }^{5}$ Clermont Auvergne University, EA 3533, Laboratory of the Metabolic Adaptations to Exercise under Physiological and Pathological Conditions (AME2P), ClermontFerrand, France; CRNH-Auvergne, Clermont-Ferrand, France ${ }^{6}$ Departamento de Biociências, Universidade Federal de São Paulo, Campus Baixada Santista, Santos, SP, Brasil 7 Programa de Pós-Graduação Interdisciplinar em Ciências da Saúde, Universidade Federal de São Paulo, Campus Baixada Santista, Santos, SP, Brasi

Correspondence to: Ana Raimunda Dâmaso Programa de Pós-graduação em Nutrição, Escola Paulista de Medicina, Universidade Federal de São Paulo Rua Botucatu, $862,2^{\circ}$ andar Departamento de Fisiologia - Vila Clementino

04020-060 - São Paulo, SP, Brasil ana.damaso@unifesp.br

Raquel Munhoz da Silveira Campos Departamento de Biociências, Universidade Federal de São Paulo Campus Baixada Santista Rua Silva Jardim, 136, térreo, Vila Matias 11015-020 - Santos, SP Brasil raquel.munhoz@unifesp.br

Received on Feb/10/2021 Accepted on Aug/25/2021 


\section{INTRODUCTION}

$\mathrm{O}$

besity is a chronic disease that induces a wide range of altered metabolic and inflammatory states, with a disruption of energy balance that might limit the longterm efficacy of weight loss therapy, favouring weight regain, and leading to the establishment of a vicious cycle (1). The worldwide prevalence of obesity continues to increase significantly in children, adolescents and adult populations $(2,3)$. Moreover, obesity, especially extreme obesity, may coexist with other chronic diseases such as diabetes mellitus, hypertension, cardiovascular and non-alcoholic fatty liver diseases (4).

Interestingly, although leptin was identified more than twenty years ago as a key factor in the control of energy balance, studies have shown hyperleptinemia to be correlated with pro-inflammatory conditions in people with obesity, which may lead to the development of atherosclerosis. Inversely, adiponectin has a potent anti-inflammatory action and inhibits insulin resistance in obesity. It is important to note that both hyperleptinemia and hypoadiponectinemia are associated with obesity and metabolic syndrome in adolescents and adults (5).

Atrial natriuretic peptide (ANP) is a protein predominantly secreted by cardiomyocytes with a genetically specific structure and function, and is known for its role in the cardiovascular system. Recently, it has emerged that ANP not only has a cardiovascular role, but also acts in energy metabolism, glucose homeostasis and insulin sensitivity in organs such as adipose tissue, skeletal muscle and the liver. Evidence suggests that its role in energy dissipation is related to enhanced lipid oxidation and mitochondrial respiration in both brown and white adipose tissue, promoting increased muscular oxidative capacity. Indeed, a study demonstrated that natriuretic peptides developed antiinflammatory actions that could promote the inhibition of inflammasome activation, including in obesity. Taken together, this evidence suggests that ANP is an important endocrine hormone that has been shown to meditate inflammatory processes and thermogenesis in clinical and experimental conditions (6-9).

Interestingly, since its discovery almost 50 years ago, fibroblast growth factor (FGF) has been shown to be a potential endocrine regulator of many physiological and pathological conditions, including diabetes, obesity, non-alcoholic fatty liver diseases and metabolic syndrome (10). Corroborating this, a previous review of publications reported that FGF2l is considered a biomarker of many metabolic diseases, and experimental studies have shown that the administration of FGF21 in obesity can reduce body weight, glucose and triglyceride, improve insulin sensitivity and increase the mass of brown adipose tissue $(3,11)$.

Strong evidence supports the idea that FGF2I may orchestrate many actions in both physiological and pathological conditions $(12,13)$. In the present investigation, our aim was to analyse the effects of an interdisciplinary intervention on biomarkers of energy balance and inflammatory states such as leptin, adiponectin and ANP, according to the FGF2l response in women with overweight and obesity by dividing the sample into two groups after the intervention: those with increased FGF21 and those with decreased FGF21.

\section{SUBJECTS AND METHODS}

This study consists of a 12 -week clinical interdisciplinary weight loss program delivered by a team comprising an endocrinologist, nutritionist and exercise physiologist. All procedures were in accordance with the Declaration of Helsinki and were approved by the Ethics and Research Committee of the Federal University of São Paulo (CEP n ${ }^{\circ} 0305 / 2017$; CAAE $\mathrm{n}^{\mathrm{o}}$ 66605916.3.0000.5505). All volunteers signed an informed consent form.

\section{Population}

The present study comprised adult women (20 to 46 years old), recruited through advertisements in the media (newspapers, magazines, radio, television and social media). The sample size calculation was performed using the GPower 3.1.9.2 program with the following parameters: an effect size of 0.30 , according to a previous publication (14), an observed power of 0.85 , and a level of significance of $5 \%$ in respect of the analysis of variance (ANOVA two-way) model for the two groups. The sample size obtained was 28 , and were separated into two groups for analysis at the end of the study: those with increased FGF21, and those with decreased FGF21.

The volunteers lived in the city of São Paulo, Brazil or nearby, so they could attend the monthly clinical interviews, and the nutritional and exercise evaluations at the university. Additionally, weekly health education information was provided to the participants via the program website on nutrition and exercise to encourage them to make long-term life-style changes. 
The inclusion criteria were to present a body mass index (BMI) value $\geq 25 \mathrm{~kg} / \mathrm{m}^{2}$ according to the World Health Organization (WHO) definition (15), to be female and aged between 20 and 46. The exclusion criteria were any disease that could compromise the results of the study (heart disease, musculoskeletal deformities, diseases related to the immune system, and genetic or endocrine diseases such as Cushing's disease and Addison's disease, identified by a physician). The major reasons for dropout were family and financial problems, followed by job opportunities.

\section{Clinical protocol}

The volunteers underwent two evaluations, one before and one after the intervention protocol (12th week). The evaluations comprised anthropometric measures (body weight, BMI, and circumferences - neck, waist, abdomen and hip); body composition; and blood samples were collected to analyze glucose metabolism and the inflammatory biomarkers leptin, adiponectin, ANP and FGF21. In addition, during the treatment, the volunteers received clinical support in the University from the interdisciplinary team to deal with any problems or doubts, and provide individual and group orientations (1st, 6th, 12th weeks) (Figure 1).

It is important to highlight that during the evaluations, questionnaires were applied (data not shown) that could identify some symptoms of problems commonly associated with obesity (such as depression symptoms, and body image concerns) and if a need for psychological counselling was identified by the study team, it was recommended to the volunteer.

\section{Anthropometric measures}

Body mass was measured using light clothes and barefoot on a Filizola ${ }^{\circledR}$ scale accurate to $0.1 \mathrm{~kg}$ and with a capacity of $180 \mathrm{~kg}$. Height was measured using a wallmounted height board $\left(\right.$ Sanny $\left.{ }^{\circledR}\right)$ to the nearest $0.1 \mathrm{~cm}$. BMI was then calculated as body mass $/$ height $^{2}$. Neck, waist, abdominal and hip circumferences were measured with a flexible, inelastic tape (16).

\section{Body composition}

Body composition and basal metabolic rate were measured using a Biodynamics $310 \mathrm{e}^{\circledast}$ bio-impedance meter (TBW, Sao Paulo, Brazil).

\section{Serum analysis}

Blood samples were collected at the outpatient clinic at approximately 8:00 a.m. after an overnight fast $(12 \mathrm{~h})$. Glucose and insulin concentrations were assessed using commercial kits. Insulin resistance was assessed with the homeostasis model of assessment of insulin resistance (HOMA-IR) calculated using the fasting blood glucose (FBG) and the immunoreactive insulin $(\mathrm{I})$ as: $[\mathrm{FBG}$ (in milligrams per deciliter $) \times \mathrm{I}$ (in milliunits per liter)]/405. The cutoff value determined

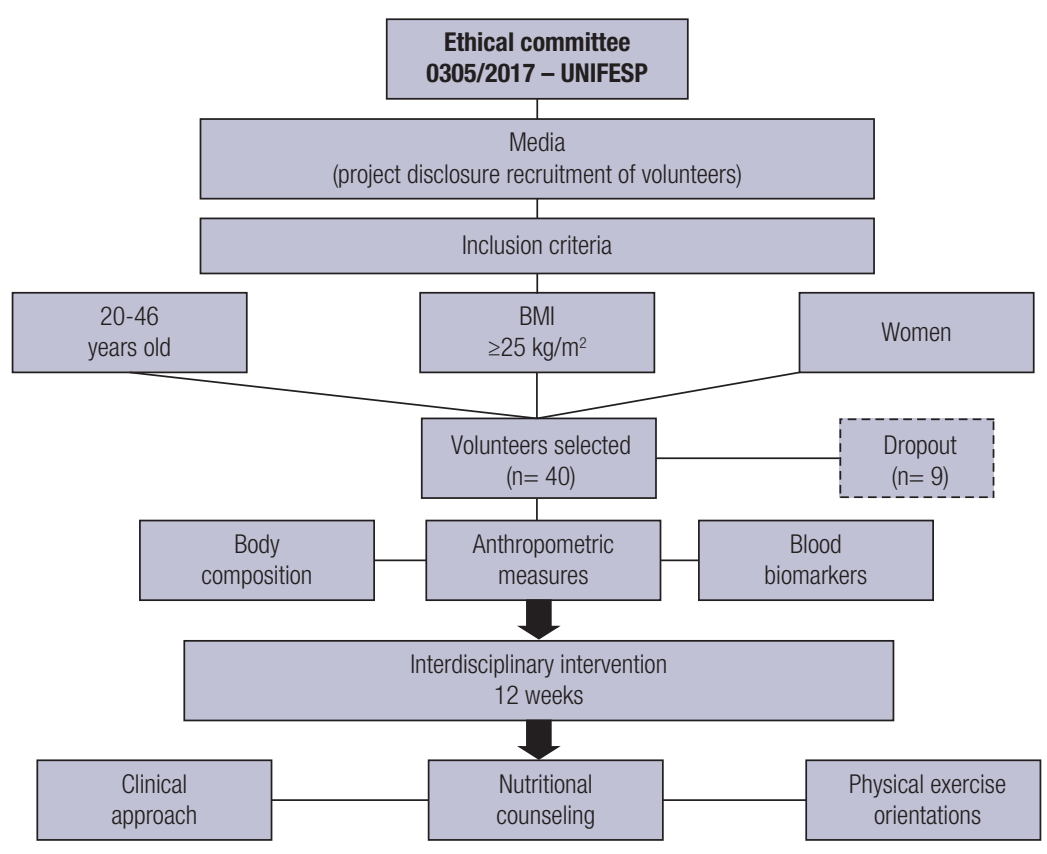

Figure 1. Methodological design. 
for classifying Brazilian subjects with insulin resistance is a HOMA-IR > 2.71 (17). The homeostasis model assessment-adiponectin (HOMA-AD) was calculated as: $[\mathrm{FBG}(\mathrm{mg} / \mathrm{dL}) \times \mathrm{I}(\mathrm{mU} / \mathrm{L})] /[405 \times$ Adiponectin concentration]. The assays of human FGF21 (BioVendor, Brno, Czech Republic, RD191108200R), adiponectin concentration (BioVendor, Brno, Czech Republic, RD195023100), ANP (Human NT-ProANP DuoSet DY8247-05 - R\&D SYSTEMS), and leptin concentration (BioVendor, Brno, Czech Republic, RD191001100) were determined by ELISA.

\section{Interdisciplinary approach}

\section{Clinical therapy}

The medical endocrinologist took an initial clinical history, and carried out a physical examination of blood pressure, cardiac frequency and body composition. Inclinic medical monitoring took place at baseline and at the end of the interdisciplinary therapy.

\section{Nutritional therapy}

At baseline, an individual nutritional consultation was carried out for behavioral nutritional analysis and to provide nutritional guidelines $(18,19)$. No pharmacotherapies, antioxidants and supplements were recommended. Each participant completed a three-day dietary record at baseline and at the end of therapy. These dietary data were transferred to a computer by the same nutritionist, and the nutrient composition was analyzed using the PC program Diet Smart (DietSmart, Copyright ${ }^{\complement}, 2012$ 2018) - based on Western and local food tables.

During the study, the volunteers participated in behavioral and motivational sessions of health education, with the nutritionists focused on the behavioral analysis of the diet, addressing the relationship between the individual and the food (20). Relevant themes of health nutrition were discussed including: 1) the principles of healthy eating; 2) differences between hunger and satiety and the importance of understanding these sensations in body weight control; 3) phases of weight loss - characteristics and fundamentals; 4) food behavior and nutrition; and 5) guidelines for achieving continuous weight loss and weight maintenance.

Once a week, volunteers also received videos with themes about nutrition and weight loss and health educational information aimed at improving eating habits and making changes to their lifestyle. Moreover, during the 12-weeks, the volunteers participated in five educational health sessions in groups, distributed throughout the clinical period, each lasting 60 minutes, conducted by the responsible nutritionist. In these interventions, themes related to nutritional practices were discussed and doubts raised by the volunteers were clarified. In addition, the group experience was a strategy to motivate volunteers during the program.

\section{Physical activity}

During the interdisciplinary therapy, the volunteers took part in five group sessions led by an exercise physiologist. Additionally, they received weekly videos with examples of exercise and health education information aimed at promoting lifestyle changes ( $>150 \mathrm{~min} /$ week$)$. The videos and groups sessions discussed themes of 1) awareness of physical exercise; 2) practice of exercise in parks; 3 ) walking and running techniques; 4) the importance of setting goals; and 5 ) recreational physical exercise.

In addition, the exercise physiologist provided information regarding the frequency, duration and kind of physical exercise that should be undertaken, as well as recommending the monitoring of heart rate. The program included exercises to develop endurance, resistance, flexibility and balance. The Borg Scale was used by the volunteers during the exercise practice to monitor training intensity (2l). Body composition variables and basal metabolic rate were used by the physiologist to recommend individual exercise training programs. The exercise modality was chosen by the volunteers according to their preferences and the recommendations of the physiologist. The program followed the recommendations of the American College of Sports Medicine $(22,23)$.

\section{Complementary health education strategies to change long-term lifestyle}

The volunteers were encouraged to make lifestyle changes that would promote their health by all the professionals in their respective domains of expertise. In addition, health education videos were provided to support changes in lifestyle, with subjects that included: 1) nutrition, physical exercise and motivation - the pillars of healthy weight loss; 2) how a healthier lifestyle can improve the way you look and feel; 3 ) how the expression of genes responsible for obesity can be increased by a lack of exercise - sedentary behavior can increase expression of a gene responsible for obesity; 4) how to choose exercises that suit you; 5 ) resistance exercise, as well as aerobic exercise, can help you to lose weight; 6) how 
to make healthy eating choices; 7) how to use the food pyramid in your favor; 8) why should I eat every three hours?; 9) learn how to assemble dishes by combining foods efficiently; 10) slow chewing is one of the steps to weight loss success; and 11) the importance of drinking water as part of your daily diet $(20,24)$.

\section{Statistical analysis}

Statistical analysis was performed using the program Statistica version 7.0 for Windows. The adopted significance value was $\boldsymbol{\alpha} \leq 5 \%$. Data normality was verified using the Shapiro-Wilk test and variable values were expressed as mean $\pm \mathrm{SD}$. Z-score were used for non-parametric data. Analysis of variance (ANOVA two-way) was applied to compare the means between the groups, followed by Fisher's post hoc test to identify the possible differences between groups. To analyze the effects of the intervention in the total sample, the T-test for dependent sample was applied (Table 1). The deltas values $(\boldsymbol{\Delta})$ were calculated as the differences after the intervention compared with baseline values $(\boldsymbol{\Delta}=$ after intervention value - baseline value) and to compare the deltas between groups the T-test for independent groups was applied (Table 2). Correlations analyses were performed using Pearson's test. The two groups were assigned according to the FGF2l response considering the values of the $\Delta \mathrm{FGF} 21$; positive values were considered in respect of increased FGF2l and negative values in respect of decreased FGF21.

\section{RESULTS}

\section{Effects of therapy in entire sample}

In respect of the entire sample, there was a statistically significant reduction in body weight $(\mathrm{p}<0.001)$; abdominal $(\mathrm{p}<0.001)$, waist $(\mathrm{p}<0.001)$, neck $(\mathrm{p}<0.001)$ and hip $(\mathrm{p}<0.001)$ circumferences; leptin concentration $(\mathrm{p}<0.001)$ and ANP $(\mathrm{p}=0.005)$. On the other hand, there were increases in adiponectin $(\mathrm{p}=0.002)$, the adiponectin/leptin ratio $(\mathrm{p}<0.001)$ and FGF2l ( $\mathrm{p}=0.04)$ (Table 1$)$.

\section{Comparison between the groups}

Variables in the two groups were similar at baseline: body weight $(\mathrm{p}=0.39)$, BMI $(\mathrm{p}=0.09)$, neck circumference $(\mathrm{p}=0.45)$, waist circumference $(\mathrm{p}=0.07)$, abdominal circumference $(\mathrm{p}=0.55)$, hip circumference $(\mathrm{p}=0.40)$,

Table 1. Analysis the effects of interdisciplinary therapy on anthropometric and metabolic profile according FGF21 response

\begin{tabular}{|c|c|c|c|c|c|c|c|c|}
\hline \multirow[b]{3}{*}{ Body weight (kg) } & \multicolumn{3}{|c|}{ All sample $(n=31)$} & \multicolumn{2}{|c|}{ Increased FGF21 group $(n=16)$} & \multicolumn{3}{|c|}{ decreased FGF21 group ( $n=15)$} \\
\hline & \multicolumn{2}{|c|}{ Baseline } & After intervention & Baseline & After intervention & \multicolumn{2}{|c|}{ Baseline } & After intervention \\
\hline & 89.73 & \pm 9.02 & $86.54 \pm 9.04^{a}$ & $88.35 \pm 8.84$ & $85.67 \pm 8.78^{a}$ & 91.20 & \pm 9.27 & $87.46 \pm 9.53^{\mathrm{a}}$ \\
\hline Body mass index $\left(\mathrm{kg} / \mathrm{m}^{2}\right)^{\star}$ & 33.64 & $\pm \quad 3.49$ & $32.44 \pm 3.48$ & $32.61 \pm 3.97$ & $31.62 \pm 3.88$ & 34.74 & \pm 2.60 & $33.31 \pm 2.87$ \\
\hline Neck circumference (cm) & 35.94 & \pm 1.53 & $35.07 \pm 1.39^{a}$ & $35.78 \pm 1.49$ & $34.84 \pm 1.28^{a}$ & 36.11 & \pm 1.60 & $35.33 \pm 1.52^{\mathrm{a}}$ \\
\hline Waist circumference (cm) & 93.91 & $\pm \quad 7.14$ & $90.10 \pm 6.12^{a}$ & $91.78 \pm 6.53$ & $88.39 \pm 6.19^{a}$ & 96.19 & \pm 7.26 & $92.08 \pm 5.62^{\mathrm{a}}$ \\
\hline Abdominal circumference (cm) & 106.93 & $\pm \quad 8.14$ & $103.19 \pm 7.51^{\mathrm{a}}$ & $105.79 \pm 8.17$ & $101.51 \pm 7.13^{\mathrm{a}}$ & 108.13 & \pm 8.21 & $105.14 \pm 7.74^{\mathrm{a}}$ \\
\hline Hip circumference (cm) & 120.22 & \pm 8.03 & $117.34 \pm 7.93^{a}$ & $119.22 \pm 8.85$ & $117.01 \pm 8.50$ & 121.29 & \pm 7.20 & $117.72 \pm 7.54^{\mathrm{a}}$ \\
\hline Body fat mass $(\%)^{\star}$ & 37.44 & $\pm \quad 4.37$ & $35.75 \pm 4.52$ & $36.74 \pm 4.57$ & $35.12 \pm 4.75$ & 38.17 & $\pm \quad 4.17$ & $36.43 \pm 4.32$ \\
\hline Body lean mass $(\mathrm{kg})^{\star}$ & 56.48 & $\pm \quad 4.86$ & $55.72 \pm 4.55$ & $56.73 \pm 5.39$ & $55.70 \pm 5.07$ & 56.22 & $\pm \quad 4.39$ & $55.73 \pm 4.16$ \\
\hline Glucose $(\mathrm{mg} / \mathrm{dL})^{\star}$ & 93.10 & \pm 10.61 & $93.52 \pm 7.15$ & $89.75 \pm 6.94$ & $92.25 \pm 6.74$ & 96.67 & $\pm 12.77^{b}$ & $94.87 \pm 7.56$ \\
\hline Insulin $(\mu \mathrm{U} / \mathrm{mL})^{*}$ & 10.83 & $\pm \quad 4.61$ & $10.28 \pm 4.36$ & $10.33 \pm 4.12$ & $10.45 \pm 3.93$ & 11.36 & \pm 5.18 & $10.11 \pm 4.88$ \\
\hline HOMA-IR & 2.51 & \pm 1.23 & $2.38 \pm 1.01$ & $2.32 \pm 1.09$ & $2.39 \pm 0.90$ & 2.72 & \pm 1.37 & $2.37 \pm 1.14$ \\
\hline HOMA-AD & 0.89 & $\pm \quad 0.85$ & $0.53 \pm 0.30$ & $0.86 \pm 0.80$ & $0.50 \pm 0.23$ & 0.91 & \pm 0.93 & $0.55 \pm 0.35$ \\
\hline Adiponectin (pg/mL) & 3.78 & \pm 1.54 & $5.04 \pm 2.04^{a}$ & $3.44 \pm 1.25$ & $5.34 \pm 2.38^{a}$ & 4.11 & \pm 1.76 & $4.74 \pm 1.68$ \\
\hline Leptin (ng/mL) & 51.48 & \pm 18.20 & $37.00 \pm 14.22^{\mathrm{a}}$ & $56.46 \pm 17.12$ & $36.03 \pm 13.75^{a}$ & 46.50 & \pm 18.45 & $37.97 \pm 15.09^{a}$ \\
\hline Adiponectin/leptin & 0.08 & $\pm \quad 0.04$ & $0.15 \pm 0.09^{a}$ & $0.06 \pm 0.03$ & $0.17 \pm 0.011^{a}$ & 0.09 & \pm 0.05 & $0.14 \pm 0.06$ \\
\hline ANP $(\mathrm{pg} / \mathrm{mL})^{*}$ & 373.18 & \pm 290.21 & $349.80 \pm 313.17^{a}$ & $353.34 \pm 203.10$ & $384.64 \pm 363.58$ & 391.59 & \pm 360.01 & $309.59 \pm 251.34^{a}$ \\
\hline FGF21 (pg/mL) & 74.32 & \pm 44.15 & $127.89 \pm 151.55^{a}$ & $68.68 \pm 50.11$ & $197.86 \pm 185.71^{a}$ & 80.33 & \pm 37.58 & $53.26 \pm 26.49^{c}$ \\
\hline
\end{tabular}


body fat mass $(\mathrm{p}=0.38)$, body lean mass $(\mathrm{p}=0.66)$, insulin $(\mathrm{p}=0.5 \mathrm{l})$, HOMA-IR $(\mathrm{p}=0.35)$, HOMA-AD $(\mathrm{p}=0.84)$, adiponectin $(\mathrm{p}=0.31)$, leptin $(\mathrm{p}=0.10)$, adiponectin/leptin $(\mathrm{p}=0.23)$, ANP $(\mathrm{p}=0.91)$ and FGF-21 $(\mathrm{p}=0.74)$. The only significant difference between groups at baseline was in respect of glucose $(\mathrm{p}$ $=0.03$ ) (Table 1 and Figure 2A-E).

After the intervention, no differences between the groups were found in respect of body weight $(\mathrm{p}=0.58)$, BMI $(\mathrm{p}=0.16)$, neck circumference $(\mathrm{p}=0.37)$, waist circumference $(\mathrm{p}=0.14)$, abdominal circumference $(\mathrm{p}=0.23)$, hip circumference $(\mathrm{p}=0.82)$, body fat mass $(\mathrm{p}=0.40)$, body lean mass $(\mathrm{p}=0.98)$, glucose $(\mathrm{p}=0.4 \mathrm{l})$, insulin ( $\mathrm{p}=0.83)$, HOMA-IR ( $\mathrm{p}=0.95)$, HOMA-AD $(\mathrm{p}=0.55)$, adiponectin $(\mathrm{p}=0.36)$, leptin $(\mathrm{p}=0.74)$, adiponectin/leptin $(\mathrm{p}=0.23)$ and ANP $(\mathrm{p}=0.75)$. Only FGF21 values were different between groups after the intervention $(\mathrm{p}<0.001)$ (Table $\mathrm{l}$ and Figure 2A-E).

\section{Effects of therapy in increased FGF21 group}

There were reductions in body weight $(\mathrm{p}=0.001)$, neck $(\mathrm{p}=0.001)$, waist $(\mathrm{p}=0.002)$ and abdominal $(\mathrm{p}<0.001)$ circumferences, and in leptin concentration $(\mathrm{p}<0.001)$. There were increases in adiponectin $(\mathrm{p}=$ $0.001)$, adiponectin/leptin ratio $(\mathrm{p}<0.001)$ and FGF21 $(\mathrm{p}<0.001)$. No differences were found for HOMA-IR, HOMA-AD and ANP (Table 1 and Figure 2A-E).

\section{Effects of therapy in decreased FGF21 group}

There were reductions in body weight $(\mathrm{p}=0.001)$, waist $(\mathrm{p}<0.001)$, abdominal $(\mathrm{p}=0.004)$ and hip $(\mathrm{p}<0.001)$ circumferences, leptin concentration $(\mathrm{p}=0.01)$ and $\operatorname{ANP}(\mathrm{p}=0.03)$. No differences were found for HOMA-IR, HOMA-AD, adiponectin and adiponectin/leptin ratio (Table 1 and Figure 2A-E).

\section{Changes in the metabolic profile according to FGF21 groups}

Comparing the effects of therapy according to the FGF2 I response, there was a greater reduction in leptin concentration $(\mathrm{p}=0.01)$, and increases in adiponectin $(\mathrm{p}=0.05)$ and the adiponectin/leptin ratio $(\mathrm{p}<0.001)$ in the increased FGF2l group (Table 2).

\section{Correlation analysis}

In the present investigation, it was found that $\Delta \mathrm{FGF} 21$ correlated positively with $\triangle \mathrm{ANP}$ considering the total sample ( $\mathrm{r} 0.82, \mathrm{p}=0.002)$, increased FGF21 group (r $0.97, \mathrm{p}=0.02$ ) and decreased FGF21 group ( $\mathrm{r} 0.73$,

Table 2. Analysis of the variables variation during interdisciplinary therapy on anthropometric and metabolic profile according FGF21 response

\begin{tabular}{|c|c|c|c|c|c|c|c|c|c|}
\hline \multirow[b]{2}{*}{ Body weight (kg) } & \multicolumn{3}{|c|}{ All sample $(n=31)$} & \multicolumn{3}{|c|}{$\begin{array}{l}\text { Increased FGF21 } \\
\qquad(n=16)\end{array}$} & \multicolumn{3}{|c|}{$\begin{array}{l}\text { Decreased FGF21 } \\
\quad(n=15)\end{array}$} \\
\hline & -3.19 & \pm & 2.99 & -2.68 & \pm & 2.61 & -3.74 & \pm & 3.35 \\
\hline Body mass index $\left(\mathrm{kg} / \mathrm{m}^{2}\right)$ & -1.20 & \pm & 1.14 & -0.99 & \pm & 0.97 & -1.43 & \pm & 1.30 \\
\hline Neck circumference (cm) & -0.75 & \pm & 0.81 & -0.79 & \pm & 0.67 & -0.72 & \pm & 0.98 \\
\hline Waist circumference (cm) & -3.51 & \pm & 3.48 & -3.07 & \pm & 3.04 & -4.02 & \pm & 4.00 \\
\hline Abdominal circumference (cm) & -3.15 & \pm & 3.78 & -3.99 & \pm & 3.16 & -2.17 & \pm & 4.32 \\
\hline Hip circumference (cm) & -2.93 & \pm & 3.90 & -2.03 & \pm & 3.13 & -3.97 & \pm & 4.54 \\
\hline Body fat mass (\%) & -1.68 & \pm & 4.21 & -1.63 & \pm & 5.06 & -1.74 & \pm & 3.25 \\
\hline Body lean mass (kg) & -0.89 & \pm & 3.96 & -1.29 & \pm & 5.13 & -0.49 & \pm & 2.43 \\
\hline Glucose (mg/dL) & 0.42 & \pm & 10.09 & 2.50 & \pm & 8.74 & -1.80 & \pm & 11.23 \\
\hline Insulin (ulU/mL) & -0.52 & \pm & 4.77 & 0.20 & \pm & 3.30 & -1.25 & \pm & 5.92 \\
\hline HOMA-IR & -0.144 & \pm & 1.24 & 0.06 & \pm & 0.8 & -0.35 & \pm & 1.54 \\
\hline HOMA-AD & -0.35 & \pm & 0.84 & -0.36 & \pm & 0.81 & -0.35 & \pm & 0.90 \\
\hline Adiponectin (pg/mL) & 1.26 & \pm & 2.11 & 1.90 & \pm & 2.30 & 0.63 & \pm & 1.74 \\
\hline Leptin (ng/mL) & -14.48 & \pm & 13.75 & -20.44 & \pm & 14.65 & -8.53 & \pm & $10.05^{d}$ \\
\hline Adiponectin/leptin & 0.07 & \pm & 0.09 & 0.10 & \pm & 0.11 & 0.04 & \pm & $0.05^{d}$ \\
\hline ANP (pg/mL) & -18.40 & \pm & 443.04 & 16.16 & \pm & 436.48 & -52.96 & \pm & 464.57 \\
\hline FGF21 (pg/mL) & 53.58 & \pm & 140.09 & 129.19 & \pm & 161.46 & -27.08 & \pm & $24.86^{d}$ \\
\hline
\end{tabular}

HOMA-IR: homeostasis model assessment-insulin resistance; HOMA-AD: HOMA-adiponectin; ANP: atrial natriuretic peptide; FGF21: human fibroblast growth factor 21. ¿Statistical difference between increased and decreased FGF21 groups. Comparisons between groups were performed by T-test for independent groups. 
A
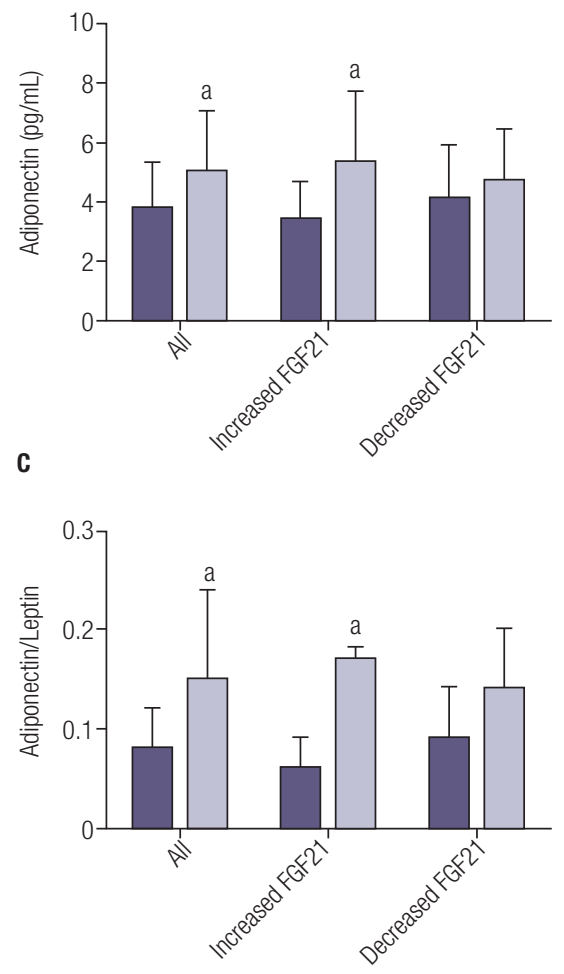

E

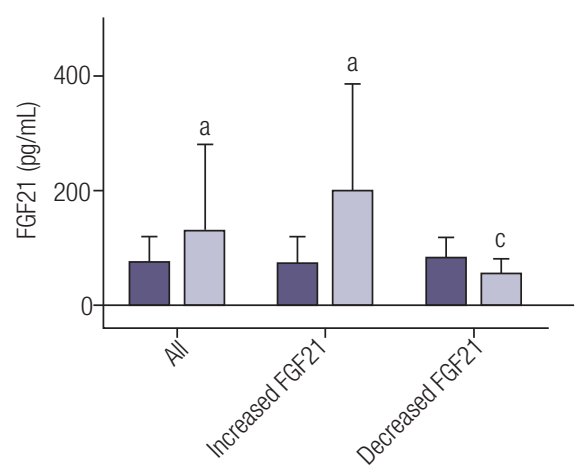

B
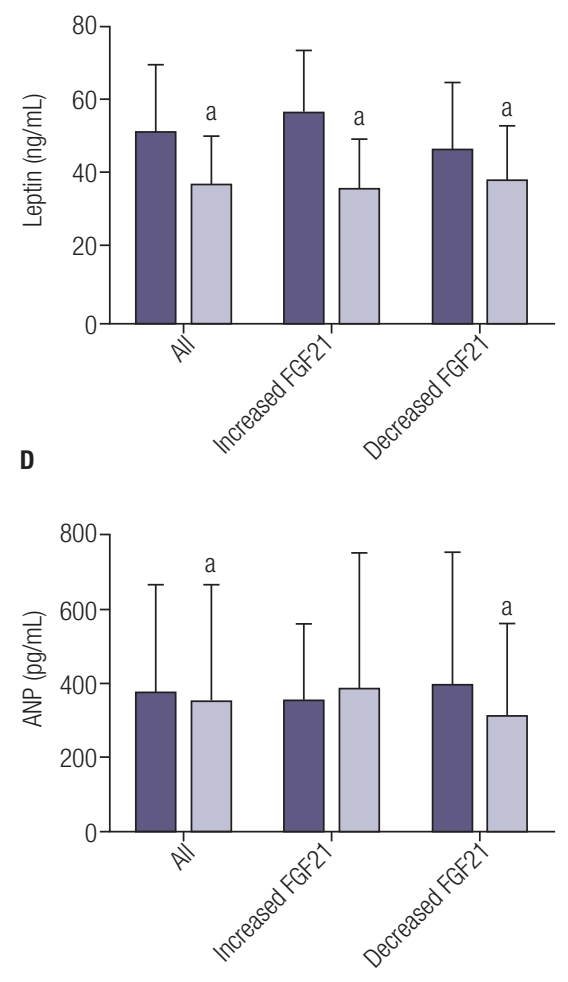

Figure 2. Effects of interdisciplinary intervention considering the entire sample, and the increased FGF21 and decreased FGF21 groups in respect of the

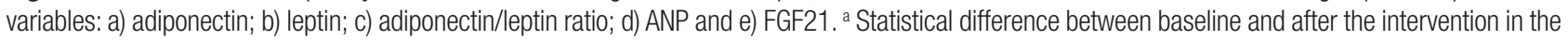
same group; c Statistical difference between groups after the intervention. ANOVA two-way followed by Fisher post hoc test and T-test for dependent sample.

$\mathrm{p}=0.04)$. In addition, $\Delta \mathrm{FGF} 2 \mathrm{l}$ correlated positively with $\Delta$ adiponectin considering the total sample ( $\mathrm{r} 0.65$, $\mathrm{p}=0.02)$. Moreover, there was a negative correlation between $\Delta$ FGF2l and $\Delta$ waist circumference in the increased FGF21 group $(\mathrm{r}-0.98, \mathrm{p}=0.01)$.

\section{DISCUSSION}

FGF21 is known to be a key mediator of energy homeostasis and inflammatory processes in metabolic diseases, and its concentration changes in healthy and unhealthy conditions. In the present study, the most important findings observed after weight loss therapy was that only the increased FGF21 group presented significant improvements in adiponectin concentration and adiponectin/leptin ratio. In line with these results, leptin concentration was significantly reduced in both the increased and decreased FGF21 groups. However, the increased FGF2 1 group, showed a greater reduction in leptin compared to the decreased FGF2l group. 
The adiponectin/leptin ratio in the increased FGF21 group after weight loss therapy was almost twice that at baseline, suggesting an improvement in inflammatory state in respect of anti-inflammatory biomarkers $(4,25)$. Although our study did not show a statistical difference after the intervention in respect of HOMA-IR, it is important to note that at baseline HOMA-IR was above cut-off values in the decreased FGF21 group but, after the intervention both groups (increased and decreased FGF-21) showed HOMA-IR values in accordance with the recommended reference values (17).

Interestingly, some experimental investigations have shown that interventions that raise circulating FGF21 levels increase insulin sensitivity and energy expenditure. In fact, it has previously been shown that FGF21 secretion by the liver may enhance blood flow and increase adiponectin secretion in the adipose tissue, increasing serum concentration. Additionally, FGF21 functions as a metabolic regulator in either an endocrine or autocrine manner in multiple organs, including blood vessels, the testes, kidneys, heart, skeletal muscle, and the brain. FGF2l acts on these organs not only by directly binding to the FGF receptors (FGFRs) of these organs in the presence of its receptor $\beta$-Klotho, but is also mediated by adiponectin or the central neural system $(26,27)$.

Adiponectin has been studied in depth and its anti-inflammatory property is well established. This hormone is decreased in obesity and various studies from the literature show a marked increase in adiponectin concentration after weight loss therapy in adolescents and adults $(28,29)$. FGF2 1 and adiponectin are among the major hormones secreted by the liver and adipose tissue, respectively (30). Mechanisms that elevate either circulating FGF2l or adiponectin have been shown to increase energy expenditure, reduce adiposity, decrease insulin resistance and hyperglycaemia, and are associated with reduced cardiovascular disease events (31).

As previously suggested by Hui and cols., both adiponectin and FGF21 are considered promising therapeutic strategies in the prevention and treatment of obesity and related comorbidities. However, the mechanism by which FGF2l promotes the expression and secretion of adiponectin is yet to be elucidated, although there is some evidence indicating that PPAR $\gamma$ may be at least partially responsible for this and be a missing link between FGF21 and adiponectin (32).
Surprisingly, in our study we found that individuals responded differently to weight loss in respect of FGF2 I concentrations, with some volunteers showing a positive $\triangle \mathrm{FGF} 2 \mathrm{l}$ and others negative values. A recent review published by Martínez-Garza and cols. (33) highlighted the potential discrepancies observed in FGF21 concentrations, and noted that the FGF21 response can be different under stressful conditions, such as nutritional deprivation, increased physical exercise and some metabolic disorders, including obesity. Other studies have shown that carbohydrate intake, fat consumption, low protein and ketogenic diets can induce different hepatic expression of FGF21 (34-38).

In respect of physical exercise, the results are contradictory, but in general they suggest that the type, frequency, intensity and duration of exercise can influence the observed response. Previously, Morville and cols. (39) demonstrated that endurance training increase FGF21, while resistance exercise seems not to alter to its concentrations in healthy humans. Kim and cols. (40) identified higher values of serum FGF2l th after recovery, but found no differences immediately after acute exercise, and also reported higher values of serum FGF21 after high-intensity exercise compared to mild-intensity exercise.

Therefore, our findings lead us to hypothesize that the different responses in respect of FGF21 concentrations observed in our study may have been the result of different nutritional and exercise choices of the volunteers, as the intervention protocol did not restrict the participants to one specific nutritional or exercise regime. In addition, possible mechanisms related to epigenetic factors may contribute (41), especially in respect of FGF21 resistance in obesity, however our data do not support this hypothesis.

Additionally, we observed a positive correlation between the delta of FGF2I and the delta of ANP in both analysed groups, with ANP maintaining the same concentration in the increased FGF2l group, while in the decreased FGF21 group, there was a significant reduction in ANP. These results suggest possible synergic effects of these biomarkers in the control of energy homeostasis and inflammatory processes in women with obesity, although this needs to be explored further in a larger sample with different degrees of obesity and weight-loss, as in the present investigation both groups presented similar reductions in body weight. 
Interestingly, previous data support the idea that the ANP secreted by the heart in response to exercise acts on both white and brown adipose tissue, increasing the secretion of PGCl-alfa, upregulating UCP-1, and enhancing the thermogenic effects in experimental and clinical conditions $(7,42)$. In fact, the natriuretic peptides were first associated with the control of hypertension in patients with cardiovascular diseases (43). In respect of obesity, the evidence indicates a negative correlation between atrial/brain natriuretic peptides and body weight and BMI. Different factors may be associated with this relationship, although regional variations in fat deposits, particularly in the visceral area, are frequently reported with this condition $(44,45)$.

Additionally, the clinical interdisciplinary weight loss therapy in the present investigation favoured improvements in some biomarkers of inflammation in the whole sample, and are in accordance with the results of previous studies $(25,46-48)$. It is important to highlight that all professionals participated in the entire research process and we believe that an interdisciplinary approach produces greater benefits for the volunteers and professionals (who were able to gain knowledge through the interactions with other professionals) when compared to isolated therapies (49).

In respect of the 12-week duration of the intervention, several other studies have reported positive results from different protocols with a similar duration, including reductions in body fat, visceral fat, body weight, BMI, lipid profile, waist circumference, leptin and adiponectin/leptin ratio (50-52). It should be noted that these robust results were found in programs that also used presential interventions that were also closely supervised by professionals.

On the other hand, semi-intensive or non-presential therapies are attractive strategies due to the lower associated costs. For example, the intervention by Turner-McGrievy and cols. (53) was based on the use of podcasts to promote weight loss and resulted in improvements in body weight, BMI, vegetable and fruit consumption and increased exercise among overweight adults. Another successful investigation, developed with overweight or obese individuals, was based on daily self-monitoring of diet and/or body weight, suggesting that this kind of intervention could serve as an effective strategy for weight loss (54). Previous studies by our group with obese adolescents found that semi-intensive therapy was effective to improve body composition, HDL-cholesterol, leptin concentration and nutritional profile, suggesting that this kind of intervention can be used to treat obesity $(46,55)$.

A limitation of the present study is the small sample size that may have compromised the identification of possible associations among the investigated variables. However, our study contributes important data on the complex interaction between obesity and FGF21.

In conclusion, our results showed that individuals with overweight/obesity submitted to weight loss therapy demonstrated different responses in relation to FGF21 levels. Furthermore, an increase in adiponectin and adiponectin/leptin ratio were only shown in the group with increased FGF21. Future studies are necessary to investigate the mechanisms involved in the action of FGF21 in obesity, and the possible interaction with inflammatory processes and energy homeostasis.

Acknowledgements: the authors would like to thank the volunteers who participated in the study.

Funding: this work was supported by the São Paulo Research Foundation - Fapesp [2017/07372-1; 2015/14309-9], the National Council for Scientific and Technological Development - CNPq [409943/2016-9; 301322/2017-1], and the Coordination of Higher Education Personnel Training - Capes.

Author contributions: ARD: conception and design, analysis and interpretation of data; drafting the article and final approval of the version to be published; PPM: conception and design, acquisition and interpretation of data, final approval of the version to be published; SOR: conception and design, acquisition and interpretation of data, final approval of the version to be published; DCLM: interpretation of data; revising it critically for important intellectual content and final approval of the version to be published; LMO: analysis and interpretation of data; revising it critically for important intellectual content and final approval of the version to be published; VTB: analysis and interpretation of data; revising it critically for important intellectual content and final approval of the version to be published; GIO: acquisition of data; revising it critically for important intellectual content and final approval of the version to be published; LT: acquisition of data; revising it critically for important intellectual content and final approval of the version to be published; DT: interpretation of data; revising it critically for important intellectual content and final approval of the version to be published; RMSC: conception and design, analysis and interpretation of data; drafting the article and final approval of the version to be published.

Disclosure: no potential conflict of interest relevant to this article was reported.

\section{REFERENCES}

1. Dâmaso AR, de Piano A, Campos RM, Corgosinho FC, Siegfried W, Caranti DA, et al. Multidisciplinary approach to the treatment 
of obese adolescents: effects on cardiovascular risk factors, inflammatory profile, and neuroendocrine regulation of energy balance. Int J Endocrinol. 2013;2013:541032.

2. Campos RMS, Oyama LM, Masquio DCL, Vicente SECF, Corgosinho FC, Kravchychyn ACP, et al. The role of insulin resistance on FGF-21 and inflammatory markers in obese adolescents undergoing multicomponent long-term weight loss therapy. Eur Med J. 2017;4:97-105.

3. Xie T, Leung PS. Fibroblast growth factor 21: a regulator of metabolic disease and health span. Am J Physiol Endocrinol Metab. 2017;313(3):E292-302.

4. de Piano A, de Mello MT, Sanches Pde L, da Silva PL, Campos RM, Carnier J, et al. Long-term effects of aerobic plus resistance training on the adipokines and neuropeptides in nonalcoholic fatty liver disease obese adolescents. Eur J Gastroenterol Hepatol. 2012;24(11):1313-24.

5. Sanches PL, de Mello MT, Elias N, Fonseca FA, Campos RM, Carnier $J$, et al. Hyperleptinemia: implications on the inflammatory state and vascular protection in obese adolescents submitted to an interdisciplinary therapy. Inflammation. 2014;37(1):35-43.

6. Cannone V, Cabassi A, Volpi R, Burnett JC Jr. Atrial Natriuretic Peptide: A Molecular Target of Novel Therapeutic Approaches to Cardio-Metabolic Disease. Int J Mol Sci. 2019;20(13):3265.

7. Coué $\mathrm{M}$, Moro C. Natriuretic peptide control of energy balance and glucose homeostasis. Biochimie. 2016;124:84-91.

8. Mezzasoma L, Talesa VN, Romani R, Bellezza I. ANP and BNP Exert Anti-Inflammatory Action via NPR-1/cGMP Axis by Interfering with Canonical, Non-Canonical, and Alternative Routes of Inflammasome Activation in HumanTHP1 Cells. Int J Mol Sci. 2020;22(1):24.

9. Pham DV, Park PH. Recent insights on modulation of inflammasomes by adipokines: a critical event for the pathogenesis of obesity and metabolism-associated diseases. Arch Pharm Res. 2020;43(10):997-1016.

10. Vinales KL, Begaye B, Bogardus C, Walter M, Krakoff J, Piaggi P. FGF21 is a Hormonal Mediator of the Human "Thrifty" Metabolic Phenotype. Diabetes. 2019;68(2):318-23.

11. Kharitonenkov A, Shanafelt AB. FGF21: a novel prospect for the treatment of metabolic diseases. Curr Opin Investig Drugs. 2009;10(4):359-64.

12. Giralt M, Gavaldà-Navarro A, Villarroya F. Fibroblast growth factor-21, energy balance and obesity. Mol Cell Endocrinol. 2015;418 Pt 1:66-73

13. Villarroya F, Gavaldà-Navarro A, Peyrou M, Villarroya J, Giralt M. The Lives and Times of Brown Adipokines. Trends Endocrinol Metab. 2017;28(12):855-67.

14. Watanabe M, Risi R, Camajani E, Contini S, Persichetti A, Tuccinardi D, et al. Baseline HOMA IR and Circulating FGF21 Levels Predict NAFLD Improvement in Patients Undergoing a Low Carbohydrate Dietary Intervention for Weight Loss: A Prospective Observational Pilot Study. Nutrients. 2020;12(7):2141

15. World Health Organization. Obesity and Overweight Fact Sheet. Available from: https://www.who.int/en/news-room/fact-sheets/ detail/obesityand-overweight. Accessed on: May 25, 2021.

16. Lohman TG, Roche AF, Martorrel R. Anthropometric standardization reference manual. Champaign, IL: Human Kinetic Books; 1988.

17. Geloneze B, Repetto EM, Geloneze SR, Tambascia MA, Ermetice MN. The threshold value for insulin resistance (HOMA-IR) in an admixtured population IR in the Brazilian Metabolic Syndrome Study. Diabetes Res Clin Pract. 2006;72(2):219-20.

18. Murphy SP, Poos MI. Dietary Reference Intakes: summary of applications in dietary assessment. Public Health Nutr. 2002;5(6A):843-9.
19. Institute of Medicine; Otten JJ, Hellwig JP, Meyers LD, eds. Dietary Reference Intakes:The Essential Guide to Nutrient Requirements. Washington, DC: The National Academies Press; 2006.

20. Rhein SO, Machado PP, Dâmaso AR, Campos RMS, Lima MS, Tock $L$, et al. Previous results of semipresential multiprofessional intervention, with an approach to a behavioral treatment in obesity. Braz J Health Rev. 2020;3(3):4102-15.

21. Stamford BA. Validity and Reliability of Subjective Ratings of Perceived Exertion During Work. Ergonomics. 1976;19:53-60.

22. Donnelly JE, Blair SN, Jakicic JM, Manore MM, Rankin JW, Smith BK; American College of Sports Medicine. American College of Sports Medicine Position Stand. Appropriate physical activity intervention strategies for weight loss and prevention of weight regain for adults. Med Sci Sports Exerc. 2009;41:459-71.

23. Kraemer WJ, Fragala MS. Personalize it: program design in resistance training. ACSM'S Health Fit. J. 2006;10:7-17.

24. Machado PP, Rhein SO, Campos RMS, Oyama LM, Boldarine VT, Masquio DCL, et al. Use of interactive digital technology as an adjunct to interdisciplinary therapy in the control of cardiometabolic risk and inflammation in women with obesity. Braz J Health Rev. 2020;3:4116-34

25. Masquio DC, de Piano A, Sanches PL, Corgosinho FC, Campos RM, Carnier J, et al. The effect of weight loss magnitude on pro-/ anti-inflammatory adipokines and carotid intima-media thickness in obese adolescents engaged in interdisciplinary weight loss therapy. Clin Endocrinol (Oxf). 2013;79:55-64.

26. Xu J, Lloyd DJ, Hale C, Stanislaus S, Chen M, Sivits G, et al. Fibroblast growth factor 21 reverses hepatic steatosis, increases energy expenditure, and improves insulin sensitivity in dietinduced obese mice. Diabetes. 2009;58:250-9.

27. Zhang F, Yu L, Lin X, Cheng P, He L, Li X, et al. Minireview: Roles of Fibroblast Growth Factors 19 and 21 in Metabolic Regulation and Chronic Diseases. Mol Endocrinol. 2015;29:1400-13.

28. da Silveira Campos RM, Landi Masquio DC, Campos Corgosinho F, de Lima Sanches $\mathrm{P}$, de Piano A, Carnier J, et al. Homeostasis Model Assessment-Adiponectin: the role of different types of physical exercise in obese adolescents. J Sports Med Phys Fitness. 2017;57:831-8.

29. Ma W, Huang T, Wang M, Zheng Y, Wang T, Heianza $Y$, et al. Twoyear changes in circulating adiponectin, ectopic fat distribution and body composition in response to weight-loss diets: the POUNDS Lost Trial. Int J Obes (Lond). 2016;40:1723-9.

30. Nishimura $T$, Nakatake $Y$, Konishi $M$, Itoh $N$. Identification of a novel FGF, FGF-21, preferentially expressed in the liver. Biochim Biophys Acta. 2000;1492:203-6.

31. Lin Z, Pan X, Wu F, Ye D, Zhang Y, Wang Y, et al. Fibroblast growth factor 21 prevents atherosclerosis by suppression of hepatic sterol regulatory element-binding protein-2 and induction of adiponectin in mice. Circulation. 2015;131:1861-71.

32. Hui X, Feng T, Liu $Q$, Gao Y, Xu A. The FGF21-adiponectin axis in controlling energy and vascular homeostasis. J Mol Cell Biol. 2016:8:110-119.

33. Martínez-Garza Ú, Torres-Oteros D, Yarritu-Gallego A, Marrero PF, Haro D, Relat J. Fibroblast Growth Factor 21 and the Adaptive Response to Nutritional Challenges. Int J Mol Sci. 2019;20:4692.

34. Uebanso T, Taketani $Y$, Yamamoto $H$, Amo K, Ominami H, Arai H, et al. Paradoxical regulation of human FGF21 by both fasting and feeding signals: is FGF21 a nutritional adaptation factor? PLoS One. 2011;6: e22976.

35. Yamazaki T, Okawa S, Takahashi M. The effects on weight loss and gene expression in adipose and hepatic tissues of very-low carbohydrate and low-fat isoenergetic diets in diet-induced obese mice. Nutr Metab (Lond). 2016;13: 78.

36. Lundsgaard AM, Fritzen AM, Sjøberg KA, Myrmel LS, Madsen L, Wojtaszewski JFP, et al. Circulating FGF21 in humans is potently 
induced by short term overfeeding of carbohydrates. Mol Metab. 2016;6:22-9.

37. Ryan KK, Packard AEB, Larson KR, Stout J, Fourman SM, Thompson AMK, et al. Dietary Manipulations That Induce Ketosis Activate the HPA Axis in Male Rats and Mice: A Potential Role for Fibroblast Growth Factor-21. Endocrinology. 2018;159:400-13.

38. Ibarra-Reynoso Ldel R, Pisarchyk L, Pérez-Luque EL, Garay-Sevilla ME, Malacara JM. Dietary restriction in obese children and its relation with eating behavior, fibroblast growth factor 21 and leptin: a prospective clinical intervention study. Nutr Metab (Lond). 2015;12:31.

39. Morville T, Sahl RE, Trammell SA, Svenningsen JS, Gillum MP, Helge JW, et al. Divergent effects of resistance and endurance exercise on plasma bile acids, FGF19, and FGF21 in humans. JCl Insight. 2018;3:e122737.

40. Kim KH, Kim SH, Min YK, Yang HM, Lee JB, Lee MS. Acute exercise induces FGF21 expression in mice and in healthy humans. PLoS One. 2013;8:e63517.

41. PłatekT, Polus A, Góralska J, Raźny U, Dziewońska A, Micek A, et al. Epigenetic Regulation of Processes Related to High Level of Fibroblast Growth Factor 21 in Obese Subjects. Genes (Basel). 2021;12(2):307.

42. Bordicchia M, Liu D, Amri EZ, Ailhaud G, Dessì-Fulgheri P, Zhang C, et al. Cardiac natriuretic peptides act via p38 MAPK to induce the brown fat thermogenic program in mouse and human adipocytes. J Clin Invest. 2012;122:1022-36.

43. Nishikimi T, Kuwahara K, Nakao K. Current biochemistry, molecular biology, and clinical relevance of natriuretic peptides. J Cardiol. 2011;57:131-40.

44. Sugisawa $T$, Kishimoto I, Kokubo $Y$, Nagumo A, Makino $H$, Miyamoto $Y$, et al. Visceral fat is negatively associated with B-type natriuretic peptide levels in patients with advanced type 2 diabetes. Diabetes Res Clin Pract. 2010;89:174-80.

45. Wang TJ, Larson MG, Levy D, Benjamin EJ, Leip EP, Wilson PW, et al. Impact of obesity on plasma natriuretic peptide levels. Circulation. 2004; 109:594-600.

46. Ferreira YAM, Kravchychyn ACP, Vicente SCF, Campos RMDS, Tock L, Oyama LM, et al. An Interdisciplinary Weight Loss Program Improves Body Composition and Metabolic Profile in Adolescents with Obesity: Associations with the Dietary Inflammatory Index. Front Nutr. 2019;6:77.
47. Masquio DC, de Piano-Ganen A, Oyama LM, Campos RM, Santamarina $A B$, de Souza $\mathrm{Gl}$, et al. The role of free fatty acids in the inflammatory and cardiometabolic profile in adolescents with metabolic syndrome engaged in interdisciplinary therapy. J Nutr Biochem. 2016;33:136-44.

48. Sanches PL, de Piano A, Campos RM, Carnier J, de Mello MT, Elias $\mathrm{N}$, et al. Association of nonalcoholic fatty liver disease with cardiovascular risk factors in obese adolescents: the role of interdisciplinary therapy. J Clin Lipidol. 2014;8:265-72.

49. Jessup RL. Interdisciplinary versus multidisciplinary care teams: do we understand the difference? Aust Health Rev. 2007;31:330-1.

50. Bharath LP, Choi WW, Cho JM, Skobodzinski AA, Wong A, Sweeney $T E$, et al. Combined resistance and aerobic exercise training reduces insulin resistance and central adiposity in adolescent girls who are obese: randomized clinical trial. Eur $\mathrm{J}$ Appl Physiol. 2018;118:1653-60.

51. Nunes PRP, Martins FM, Souza AP, Carneiro MAS, Orsatti $C L$, Michelin MA, et al. Effect of high-intensity interval training on body composition and inflammatory markers in obese postmenopausal women: a randomized controlled trial. Menopause. 2019;26:256-64.

52. Abd El-Kader SM, Al-Jiffri OH. Impact of weight reduction on insulin resistance, adhesive molecules and adipokines dysregulation among obese type 2 diabetic patients. Afr Health Sci. 2018;18:873-83.

53. Turner-McGrievy GM, Campbell MK, Tate DF, Truesdale KP, Bowling JM, Crosby L. Pounds Off Digitally study: a randomized podcasting weight-loss intervention. Am J Prev Med. 2009;37:263-9.

54. Patel ML, Brooks TL, Bennett GG. Consistent self-monitoring in a commercial app-based intervention for weight loss: results from a randomized trial. J Behav Med. 2020;43:391-401.

55. Alaby Martins Ferreira $Y$, Claudia Pelissari Kravchychyn A, de Castro Ferreira Vicente S, Munhoz da Silveira Campos R, Tock L, Missae Oyama L, et al. Influence of magnitude of weight loss on Adipo/lep ratio in adolescents with obesity undergoing multicomponent therapy. Cytokine. 2020;131:155111. 